\title{
Quercetin induces apoptosis by inhibiting MAPKs and TRPM7 channels in AGS cells
}

\author{
MIN CHUL KIM ${ }^{1 *}$, HEE JUNG LEE ${ }^{1 *}$, BORA LIM $^{1 *}$, KI-TAE HA $^{2}$, \\ SUNG YOUNG KIM ${ }^{3}$, INSUK $\mathrm{SO}^{3}$ and BYUNG JOO KIM ${ }^{1}$ \\ Divisions of ${ }^{1}$ Longevity and Biofunctional Medicine and ${ }^{2}$ Applied Medicine, Pusan National University \\ School of Korean Medicine, Yangsan 626-870; ${ }^{3}$ Department of Physiology, Seoul National University \\ College of Medicine, Seoul 110-799, Republic of Korea
}

Received November 14, 2013; Accepted March 13, 2014

DOI: $10.3892 / \mathrm{ijmm} .2014 .1704$

\begin{abstract}
The worldwide incidence and mortality rate of gastric cancer remain high, and thus, novel treatment concepts are required. Quercetin, a bioflavonoid, has been proposed to have anti-cancer properties. The aim of this study was to determine the nature of the apoptotic mechanisms responsible for the effects of quercetin on AGS cells (a commonly used human gastric adenocarcinoma cell line). AGS cell viability was assessed by MTT assay and flow cytometric analysis, mitochondrial membrane depolarization was assessed, and caspase- 3 was used to determine the involvement of apoptosis. Whole-cell configuration patch-clamp experiments were used to regulate the transient receptor potential melastatin (TRPM)7 channels. To investigate the signaling pathway of quercetininduced apoptosis in the AGS cells, western blot analysis and MTT assay were performed. Quercetin was found to induce the apoptosis of these cells, and this apoptosis was inhibited by SB203580 (a p38 kinase inhibitor), SP600125 (a JNK inhibitor) and PD98059 (an ERK inhibitor). In addition, quercetin inhibited TRPM7 currents in the AGS cells and in human embryo kidney (HEK)293 cells which overexpress TRPM7 channels. Furthermore, treatment with quercetin increased the apoptosis of HEK293 cells, which overexpress TRPM7, indicating that the upregulation of TRPM7 channels underlies quercetininduced cell death. These results suggest that quercetin plays an important pathophysiological role in AGS cells through mitogen-activated protein kinase (MAPK) signaling pathways
\end{abstract}

Correspondence to: Professor Byung Joo Kim, Division of Longevity and Biofunctional Medicine, Pusan National University School of Korean Medicine, 49 Busandaehakro, Beomeori, Mulgeum-eup, Yangsan, Gyeongsangnamdo 626-870, Republic of Korea

E-mail: vision@pusan.ac.kr

${ }^{*}$ Contributed equally

Key words: quercetin, gastric cancer, mitogen-activated protein kinase, transient receptor potential melastatin 7 and TRPM7 channels, and that quercetin has potential as a pharmacological agent for the treatment of gastric cancer.

\section{Introduction}

Gastric cancer is responsible for almost one million deaths worldwide per year. Although the age-adjusted mortality of gastric cancer has decreased over the last few decades, gastric cancer remains the second leading cause of cancer-related mortatlity (1). Gastric cancer is an asymptomatic disease during the early stages, and therefore, is often detected at a late stage. The 5-year survival rate of gastric cancer is only $20-30 \%$ (2). For these reasons, intensive research is required, in order to devise new approaches to its diagnosis and treatment. Apoptosis is a key factor that contributes to the antitumor activity of chemotherapeutic drugs and therefore, plays a key role in the search for new approaches for the treatment of cancer. In addition, as cell numbers can be regulated by factors that influence cell survival, proliferation and differentiation, apoptosis is a genedirected program that has had profound implications for our understanding of developmental biology and tissue homeostasis (3). Most anticancer agents now in use were developed using empirical screens designed to identify agents that selectively kill tumor cells (4). It is now well-established that anticancer agents induce apoptosis, and that the disruption of apoptotic programs can reduce treatment sensitivity (4). Anticancer agents induce apoptosis in normal tissues, as well as in tumors. In fact, many of the pathologists who identified apoptosis in tumors realized that apoptotic cell death was induced in a subset of normal tissues (e.g., bone marrow and the intestines), and it was suggested that the process may contribute to the 'toxicity' associated with chemotherapy (3). Although there is much more to learn, our current understanding of apoptosis provides new avenues for cancer diagnostics, prognosis and therapy. It seems likely that rational strategies to manipulate cell suicide programs will produce novel therapies that are less toxic and mutagenic than current treatment regimens (3).

Quercetin (3,3',4',5,7-pentahydroxyflavone) is a bioflavonoid, and is one of the most widely distributed dietary polyphenolics; for example, it is found in vegetables, fruits, tea and wine (5). Research into the anticarcinogenic potential of flavonoids with animal and cellular model systems supports a protec- 
tive role against the progression of colorectal cancer (6-9). Apart from other flavonoids, quercetin has been proposed to have anti-atherogenic, anti-inflammatory, antihypertensive, and anticancer effects (3). Quercetin has been reported to protect against important diseases, including lung and colon cancers (10-12). In addition, quercetin has been shown to inhibit human breast cancer cell proliferation and to induce apoptosis through the regulation of Bcl-2 and Bax (13).

However, the effects of quercetin on human gastric adenocarcinoma cells have not yet been fully elucidated. Therefore, in this study, we investigated the effects of quercetin in human gastric adenocarcinoma cells and the mechanisms responsible for its activities.

\section{Materials and methods}

Materials. Quercetin was purchased from Alexis Biochemicals (Vinci Biochem, Florence, Italy) and PD98059 (ERK inhibitor), SB203580 (p38 kinase inhibitor), and SP600125 (JNK inhibitor) were purchased from Tocris Bioscience (Bristol, UK). All other agents were purchased from Sigma-Aldrich (St. Louis, MO, USA).

Cells. The AGS cell line (a human gastric adenocarcinoma cell line) was established at the Cancer Research Center, College of Medicine, Seoul National University, Seoul, Korea, and propagated in RPMI-1640 medium (Gibco-BRL, Carlsbad, CA, USA) supplemented with $10 \%$ heat-inactivated fetal bovine serum containing $20 \mu \mathrm{g} / \mathrm{ml}$ penicillin and streptomycin in a $5 \% \mathrm{CO}_{2}$ atmosphere at $37^{\circ} \mathrm{C}$.

3-(4,5-Dimethylthiazol-2-yl)-2,5-diphenyltetrazolium bromide (MTT) assay. Cell viability was assessed by MTT assay. The AGS or human embryo kidney (HEK)293 cells were seeded into each well of 12-well culture plates and then cultured in RPMI-1640 supplemented with $10 \%$ heat-inactivated fetal bovine serum containing $20 \mu \mathrm{g} / \mathrm{ml}$ penicillin and streptomycin for $72 \mathrm{~h}$. MTT solution [100 $\mu \mathrm{l} ; 5 \mathrm{mg} / \mathrm{ml}$ in phosphate-buffered saline (PBS)] was then added to each well, and the plates were incubated at $37^{\circ} \mathrm{C}$ for $4 \mathrm{~h}$. After removing the supernatant and shaking with $200 \mu 1$ of dimethyl sulfoxide (Jersey Lab Supply, Livingston, NJ, USA) for $30 \mathrm{~min}$, and absorbances were measured at $570 \mathrm{~nm}$. All experiments were repeated at least 3 times.

Flow cytometric analysis. In order to investigate the effects of treatment on the cell cycle of the AGS cells, flow cytometric analysis was performed with propidium iodine (PI) staining, as previously described $(14,15)$. The cells $\left(1 \times 10^{6}\right)$ were placed in an Eppendorf tube, and $700 \mu \mathrm{l}$ of ice-cold fixation buffer (ethyl alcohol) was slowly added with vortexing. The tubes were sealed with parafilm, incubated at $4^{\circ} \mathrm{C}$ overnight, spun for $3 \mathrm{~min}$ at $106 \mathrm{x} \mathrm{g}$ at $4^{\circ} \mathrm{C}$, and the supernatants were aspirated and discarded. Cell pellets were resuspended in $200 \mu \mathrm{l}$ of PI staining solution [ $2 \mu \mathrm{l}$ of PI $(5 \mathrm{mg} / \mathrm{ml})$ and $2 \mu \mathrm{l}$ of RNase in a total of $196 \mu \mathrm{l}$ of PBS] and centrifuged at 2,0817 $\mathrm{x}$ g for $5 \mathrm{sec}$. After being kept for $30 \mathrm{~min}$ in the dark at room temperature, the samples were analyzed using a fluorescence-activated cell sorter (FACScan; Becton-Dickinson, Mountain View, CA, USA) at $\lambda=488 \mathrm{~nm}$ using Cell-Quest software (BectonDickinson). The DNA content distribution of normally growing AGS cells is characterized by 2 peaks, representing the G1/G0 and G2/M phases. The G1/G0 phase is composed of cells in the resting state of the cell cycle and has the greatest diploid DNA content, whereas the DNA content in the G2/M phase is more than diploid. Cells in the sub-G1 phase have the least DNA content, which is termed hypodiploid (a hypoploid DNA content represents DNA fragmentation) (16).

Assessment of mitochondrial membrane depolarization. Mitochondrial membrane depolarization was evaluated using the JC-1 fluorescence probe according to the manufacturer's instructions (Santa Cruz Biotechnology, Inc., Santa Cruz, CA, USA). The AGS cells were labeled with $2 \mu \mathrm{M} \mathrm{JC}-1$ for $30 \mathrm{~min}$ at $37^{\circ} \mathrm{C}$ and then analyzed by flow cytometry at excitation and emission wavelengths of $530 / 30$ or $585 / 42 \mathrm{~nm}$ and $488 \mathrm{~nm}$, respectively. The cells without red fluorescence were regarded to manifest mitochondrial membrane depolarization.

Caspase assay. Caspase-3 kits (Cellular Activity Assay kit PLUS) were purchased from Biomol International (Plymouth Meeting, PA, USA). After the treatments, the cells were centrifuged (10,000 x g, $\left.4^{\circ} \mathrm{C}, 10 \mathrm{~min}\right)$, washed with PBS, resuspended in ice-cold cell lysis buffer, incubated on ice for $10 \mathrm{~min}$, centrifuged at $10,000 \mathrm{x} \mathrm{g}\left(4^{\circ} \mathrm{C}, 10 \mathrm{~min}\right)$, and the supernatants were removed. The supernatants $(10 \mu \mathrm{l})$ were then incubated with $50 \mu \mathrm{l}$ of substrate (400- $\mu \mathrm{M}$ Ac-DEVD-pNA) in $40 \mu \mathrm{l}$ of assay buffer at $37^{\circ} \mathrm{C}$. Absorbance was read at $405 \mathrm{~nm}$ at several time points. The pNA concentration in the samples was determined using a standard pNA concentration vs. absorbance plot. The pan-caspase inhibitor, zVAD-fmk (Calbiochem, La Jolla, CA, USA), was used to validate the assay method.

Patch-clamp experiments. Whole-cell configuration patch-clamp experiments were performed at room temperature $\left(22-25^{\circ} \mathrm{C}\right)$. The AGS cells were transferred to a small chamber on an inverted microscope stage (IX70; Olympus, Tokyo, Japan), and constantly perfused with a solution containing (mmol/l) $\mathrm{KCl} 2.8, \mathrm{NaCl} 145, \mathrm{CaCl}_{2} 2$, glucose 10, $\mathrm{MgCl}_{2} 1.2$ and HEPES 10 (adjusted to $\mathrm{pH} 7.4$ with $\mathrm{NaOH}$ ). The pipette solution contained (mmol/l) Cs-glutamate 145 , $\mathrm{NaCl}$ 8, Cs-2-bis(2-aminophenoxy)-ethane-N,N,N',N'-tetraacetic acid 10 and HEPES-CsOH 10 (adjusted to $\mathrm{pH} 7.2$ with $\mathrm{CsOH}$ ). An Axopatch I-D (Axon Instruments, Foster City, CA, USA) was used to amplify the membrane currents and potentials. pClamp software version 9.2 and Digidata 1322A (Axon Instruments) were used for data acquisition and to apply command pulses. The results were analyzed using pClamp and Origin software (Microcal Origin version 6.0).

Transient receptor potential melastatin (TRPM)7 expression in HEK293 cells. The HEK293 cells were transfected with Flag-murine LTRPC7/pCDNA4-TO construct and grown on glass coverslips in Dulbecco's modified Eagle's medium supplemented with $10 \%$ fetal bovine serum, blasticidin $(5 \mu \mathrm{g} / \mathrm{ml})$ and zeocin $(0.4 \mathrm{mg} / \mathrm{ml})$. TRPM7 (LTRPC7) expression was induced by the addition of $1 \mu \mathrm{g} / \mathrm{ml}$ tetracycline to the culture medium. Whole-cell patch-clamp experiments were performed at $21-25^{\circ} \mathrm{C}$ using cells grown on glass coverslips.

Sodium dodecyl sulfate-polyacrylamide gel electrophoresis and western blot analysis. Western blot analysis was 

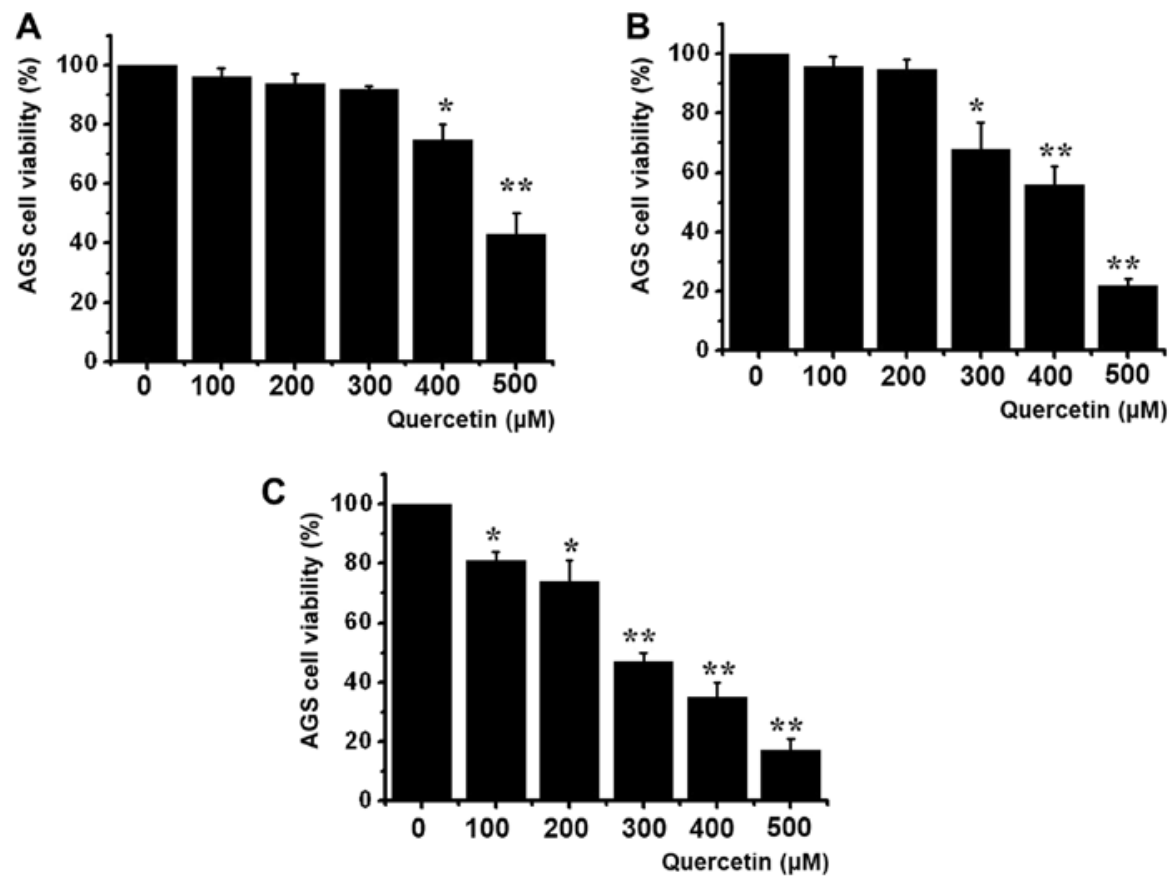

Figure 1. Effects of quercetin on AGS cell viability. MTT-based viability assay. AGS cells were treated with increasing concentrations of quercetin for (A) $24 \mathrm{~h}$, (B) $48 \mathrm{~h}$, or (C) $72 \mathrm{~h} .{ }^{*} \mathrm{P}<0.05,{ }^{* *} \mathrm{P}<0.01$.

performed using AGS cell lysates. Proteins were separated by sodium dodecyl sulfate-polyacrylamide gel electrophoresis by using $8 \%$ polyacrylamide gels, transferred onto polyvinylidene difluoride membranes, and quantified by incubating the membranes with the indicated antibodies. Antibodies against poly(ADP-ribose) polymerase (PARP), p-p38, p-JNK, p-ERK, p38, ERK and $\beta$-actin were purchased from Cell Signaling Technology (Danvers, MA, USA). Antibodies against JNK and GAPDH were obtained from Santa Cruz Biotechnology. The data are representative of at least 3 independent experiments.

Statistical analysis. Data are expressed as the means \pm SEM. The Student's t-test was used to determine the significances of the differences. Statistical significance was set at $\mathrm{P}<0.05$.

\section{Results}

Quercetin induces AGS cell death. To ascertain whether quercetin kills AGS cells, we performed MTT assays. Viable cell populations were gradually reduced by quercetin in a concentratio- and a time-dependent manner at 24, 48 and $72 \mathrm{~h}$ with an $\mathrm{IC}_{50}$ value of $267 \mu \mathrm{M}$ (Fig. 1).

Quercetin induces apoptosis of AGS cells. To determine whether the AGS-induced cell death was due to apoptosis, we conducted sub-G1 analysis, as previously described $(17,18)$. Briefly, the cells were incubated with quercetin and stained with a fluorescent DNA stain (PI). Endogenous endonucleases in apoptotic cells cleave DNA into endonucleosomal fragments. The loss of DNA is detected by FACS analysis, as a reduction of nuclear staining in apoptotic cells, which results in a novel (sub-G1) fluorescence peak to the left of the regular fluorescence peak. Flow cytometric analysis revealed that the percentage of cells in the sub-G1 phase markedly increased in a dose-dependent manner in the cells treated with quercetin (Fig. 2A). In addition, quercetin elevated mitochondrial membrane depolarization, an early event of intrinsic apoptotic signaling (Fig. 2B). Thus, our findings suggest that quercetin induces apoptosis through intrinsic apoptotic mechanism(s). In addition, using a synthetic substrate, we examined caspase-3 activity (caspase-3 activation is a hallmark of apoptotic cell death) in the AGS cells. Quercetin increased the activity of caspase-3, which was suppressed by zVAD-fmk (a pan-caspase inhibitor) (Fig. 2C). We also examined changes in caspase-3 activity by western blot analysis for its natural substrate, PARP, which has been shown to function as a cellular target of caspase-3 and other caspases. During apoptosis, PARP is proteolytically cleaved from its $116-\mathrm{kDa}$-intact form into 85 and $25 \mathrm{kDa}$ fragments. Following incubation with quercetin for $72 \mathrm{~h}$, the AGS cells showed increased PARP cleavage (Fig. 2D).

Involvement of mitogen-activated protein kinases (MAPKs) in quercetin-induced apoptosis of AGS cells. To investigate the signaling pathway of quercetin-induced apoptosis in AGS cells, we assessed the effects of quercetin on MAPKs, as they play critical roles in the apoptosis-related signaling pathway. As shown in Fig. 3, quercetin markedly increased the phosphorylation levels of p38, JNK and ERK (Fig. 3). As the role of MAPK signaling in the quercetin induced apoptosis of AGS cells has been little characterized in this study (Fig. 3), we performed MTT assays using MAPK inhibitors to assess the effects of MAPK signaling on quercetin signaling. MTT assays revealed that exposure to quercetin with SB203580 (Fig. 4A), SP600125 (Fig. 4B) and PD98059 (Fig. 4C) resulted in an increase in the viable cell populations.

Effects of quercetin in TRPM7 currents on AGS cells and HEK293 cells overexpressing TRPM7. In a previous study, 

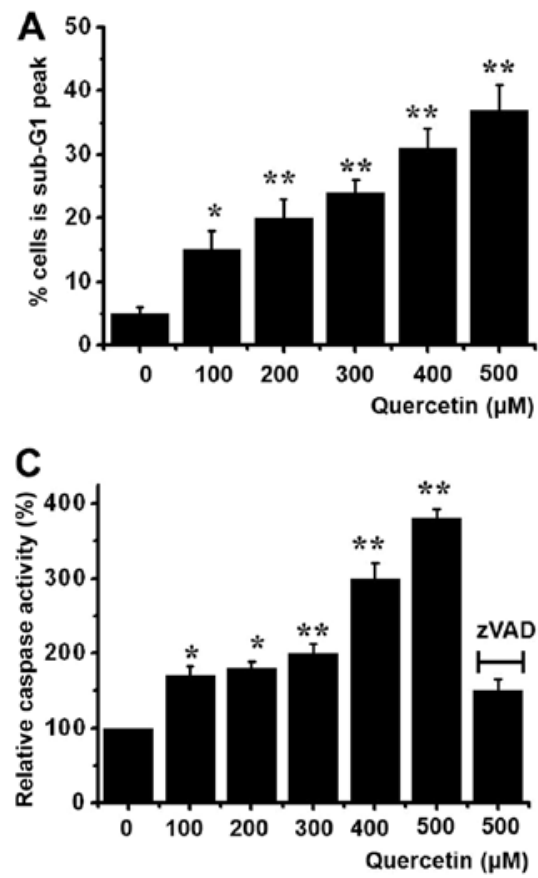

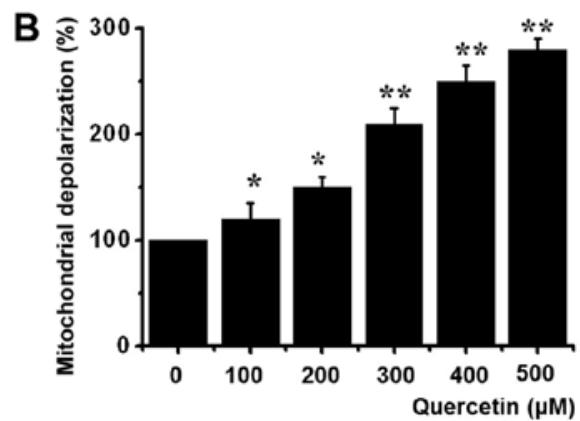

D

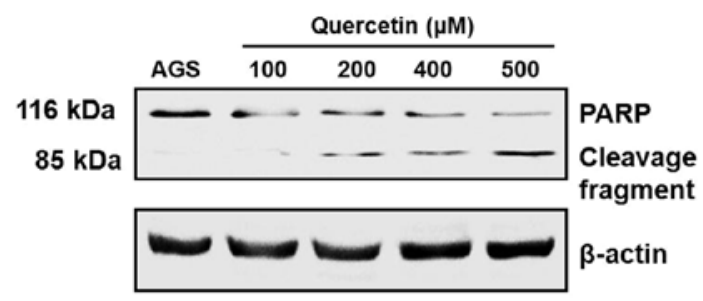

Figure 2. Quercetin induces apoptosis in AGS cells. (A) Sub-G1 peak obtained using a FACScan. (B) Mitochondrial membrane depolarization is expressed relative to the value of untreated cells. (C) Cells were cultured with quercetin at the indicated concentrations for $72 \mathrm{~h}$ prior to caspase assays. The caspase activities of untreated cells are expressed as $100 \%$. The pan-caspase inhibitor, zVAD-fmk (zVAD), at $20 \mu \mathrm{M}$ was used to validate the analytical method employed. (D) A representative western blot of cells transfected with anti-PARP antibody. Cells incubated with quercetin showed increased PARP cleavage. $\beta$-actin was used as an internal control. Experiments were performed in triplicate. Results are expressed as the means $\pm \mathrm{SEM}$. ${ }^{*} \mathrm{P}<0.05,{ }^{* *} \mathrm{P}<0.01$.

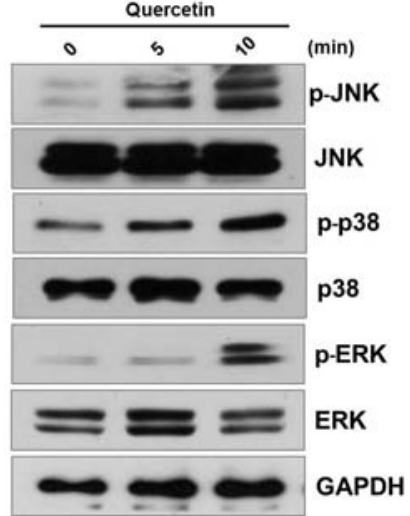

Figure 3. Effects of MAPK activation on quercetin signaling in AGS cells. The cells were treated with quercetin for the indicated times prior to western blot analysis.

we found that AGS cells express the TRPM7 channel, which is known to be essential for cell survival and has been suggested as a pharmacological target for the treatment of gastric cancer (19). Therefore, in this study, we investigated whether quercetin influences TRPM7 currents in AGS cells. To confirm the effects of quercetin on TRPM7 currents, we investigated the effects of quercetin in AGS cells using patch-clamp techniques. First, to examine the effects of internal $\mathrm{Mg}^{2+}$ on TRPM7-like currents, $\mathrm{Mg}^{2+}$ was added to the pipette solution at different concentrations from 0 to $2 \mathrm{mM}$. Current amplitudes were indeed larger at the lower concentration, and the presence of $2 \mathrm{mM} \mathrm{Mg}^{2+}$ in the pipette solution significantly inhibited the current ( $n=4$; Fig. 5A). Whole cell voltage-clamp recordings were then taken to investigate the effects of quercetin on TRPM7-like currents in AGS cells. A voltage ramp from +100 to $-100 \mathrm{mV}$ evoked small inward currents at negative potentials, whereas larger outward currents were evoked at positive potentials, showing outwardly rectifying cation currents ( $n=6$; Fig. 5B). However, in the presence of $500 \mu \mathrm{M}$ quercetin, the amplitudes of these currents were inhibited outwardly by $79.3 \pm 1.3 \%$ and inwardly by $89.2 \pm 1.4 \%$ (n=6; Fig. $5 B$ ). Furthermore, similar results were obtained withthe HEK293 cells overexpressing TRPM7 channels (Fig. 5C). To provide additional evidence supporting the positive contribution made by TRPM7 channels to quercetin toxicity, we investigated the effects of different TRPM7 channel levels on quercetin-mediated cell death. For this purpose, we used HEK293 cells with inducible TRPM7 channel expression $(20,21)$. In the absence of induced TRPM7 channel expression [TRPM7(-) cells, Tet(-)], quercetin did not induce HEK293 cell death, as shown by MTT assay $(n=6$; Fig. 5D). However, when TRPM7 channel overexpression was induced by the addition of tetracycline [TRPM7(+) cells, Tet(+)], quercetin markedly induced more HEK293 cell death, indicating that TRPM7 channel levels are positively associated with quercetin-induced cell death.

\section{Discussion}

Quercetin is a polyphenolic flavonoid that is found in fruits and vegetables, such as, apples, blueberries, broccoli, grapes, leeks, lettuce, onions and tomatoes. The mechanisms underlying the cancer-preventive effects of quercetin and other flavonoids are believed to be associated with antioxidant effects, the inhibition of enzymes that activate carcinogens, the modification of 

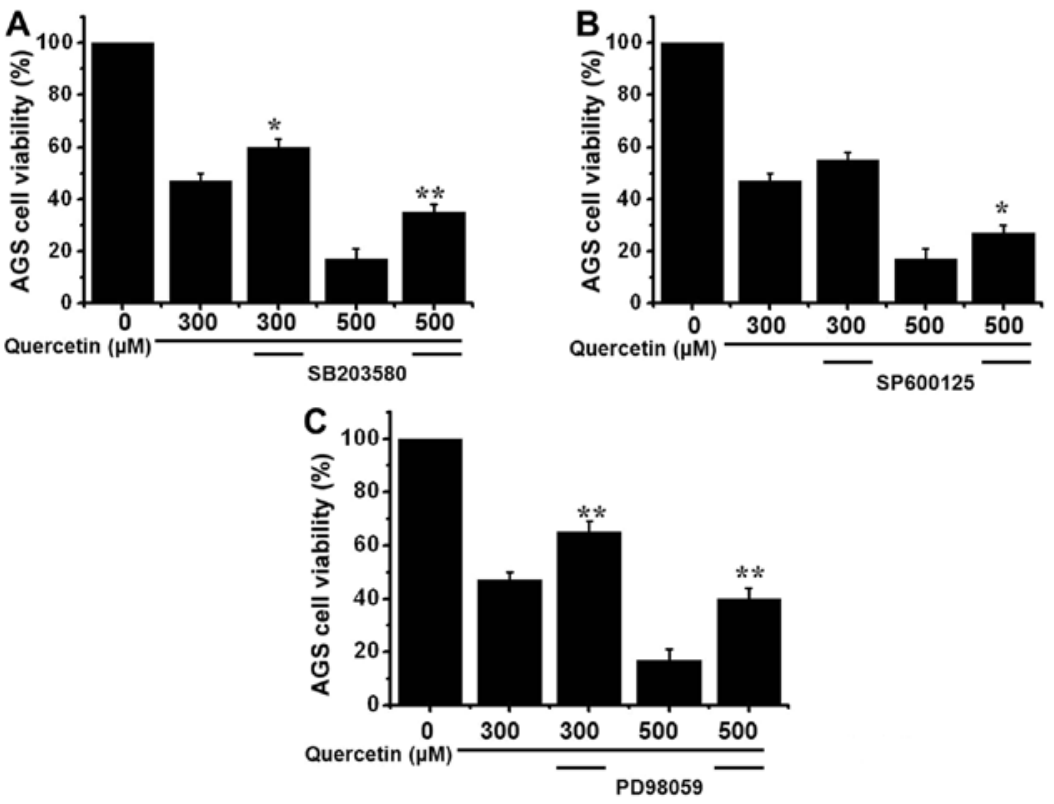

Figure 4. Effects of SB203580 (p38 kinase inhibitor), SP600125 (JNK inhibitor) and PD98059 (ERK inhibitor) on quercetin-induced AGS cell apoptosis. MTTbased viability assay. (A) SB203580, (B) SP600125 or (C) PD98059 were administered to the AGS cells pre-treated with quercetin. ${ }^{*} \mathrm{P}<0.05,{ }^{* * *} \mathrm{P}<0.01$.

A

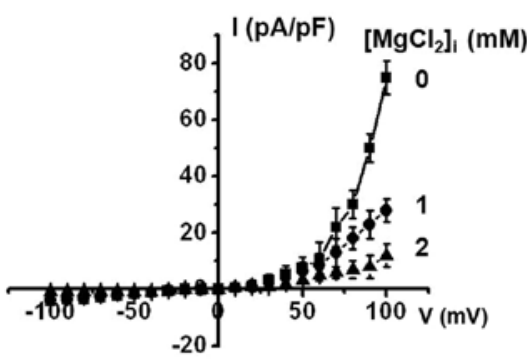

C

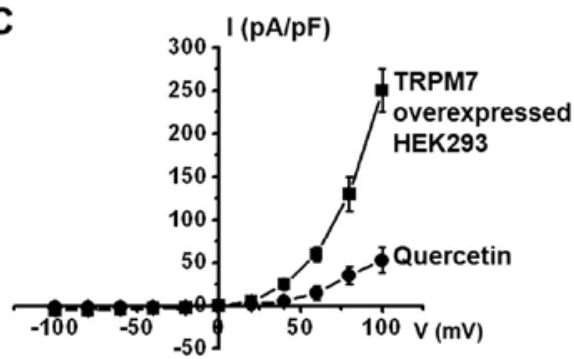

B
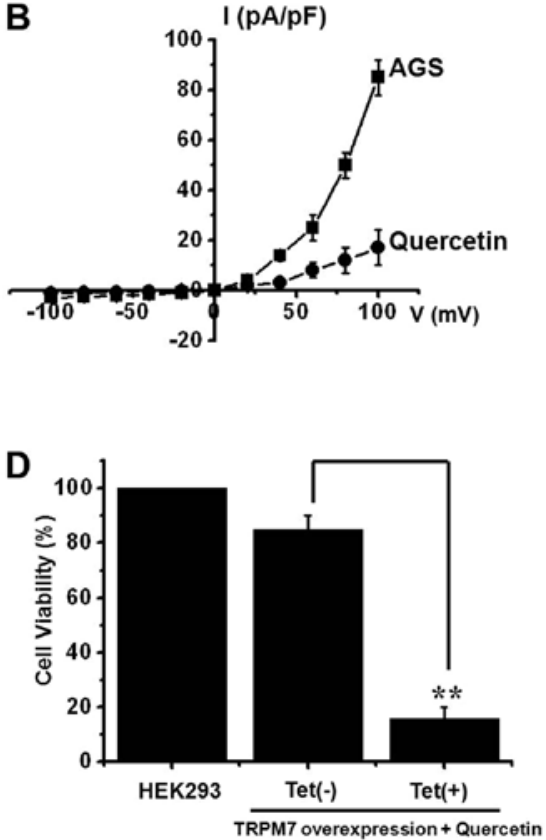

Figure 5. Effects of quercetin on AGS cells and HEK293 cells overexpressing TRPM7. (A) Representative TRPM7-like currents in ICCs at 0, 1, or 2 mM [Mg $\left.{ }^{2+}\right]_{\mathrm{i}}$. A voltage ramp from +100 to $-100 \mathrm{mV}$ was applied from a holding potential of $-60 \mathrm{mV}$. (B) Representative I-V associations showing the effect of quercetin on TRPM7 currents in AGS cells. (C) Representative I-V associations of the effect of quercetin on TRPM7 currents in HEK293 cells. (D) TRPM7 channels were upregulated by treating the cells with tetracycline for $24 \mathrm{~h}$. Cells were incubated with quercetin for $72 \mathrm{~h}$ and cell viability was determined by MTT assay.

signal transduction pathways, and interactions with receptors and/or proteins $(22,23)$. However, the effects of quercetin on AGS human adenocarcinoma cells have not yet been fully elucidated. Quercetin has been shown to exert antiproliferative effects on the parental EPG85-257P cell line and its daunorubicin-resistant variant, EPG85-257RDB, mainly through the induction of apoptosis (24). Quercetin has also been shown to induce the apoptosis of BGC-823 cells and decrease the $\mathrm{Bcl}-2$ / Bax ratio with the increased expression of caspase-3 (25).
As previously demonstrated, quercetin induced pronounced pro-apoptotic effects by activating the mitochondrial pathway in AGS and MKN28 gastric cancer cells. Treatment with quercetin induced the appearance of autophagic vacuoles, the formation of acidic vesicular organelles, the conversion of LC3-I to LC3-II, the recruitment of LC3-II to the autophagosomes, as well as the activation of autophagy genes, suggesting that quercetin initiates autophagic progression in gastric cancer cells (26). However, to our knowledge, there are no studies 
available on the association of MAPK and TRP channels in quercetin-induced apoptosis in gastric cancer cells.

Certain studies have suggested that MAPK activation plays a role in the apoptosis of cancer cells $(27,28)$. PKI 166 induced apoptosis through the activation of the p53, MAPK and caspase pathway in epidermoid carcinoma (27). In addition, isoorientin induced mitochondrial-mediated apoptosis through MAPK signaling pathways in human hepatoblastoma cancer cells (28). Thus, in this study, we investigated whether MAPKs play a role in quercetin-induced apoptosis in AGS cells. The 3 principal ubiquitously expressed MAPKs are p38 MAPK, JNK and ERK and JNK (29), and in the present study, inhibitors of p38, JNK and ERK inhibited AGS cell apoptosis induced by quercetin.

TRP channels were first cloned from the Drosophila species, and constitute a superfamily of proteins that encode a diverse group of $\mathrm{Ca}^{2+}$-permeable non-selective cation channels (NSCCs) (30). Based on their amino acid sequences, the TRP superfamily can be divided into 7 subfamilies: the TRPC ('Canonical'), TRPM ('Melastatin'), TRPV ('Vanilloid'), TRPP ('Polycystin'), TRPML ('Mucolipin'), TRPA ('Ankyrin') and the TRPN ('NOMPC') families (31). TRPM7, a member of the TRPM ion channel subfamily, is a widely expressed bifunctional protein with both ion channel and $\alpha$-kinase domains $(20,21)$. In a previous study [Kim et al (19)], we reported that human gastric adenocarcinoma cells express TRPM7 channels and that this channel is essential for cell survival. It was also suggested that this channel be viewed as a potential target for the pharmacological treatment of gastric cancer.

The TRPM7 channel is widely expressed in various tissues, including those of the brain, spleen, kidneys, lungs, liver and heart (20,32). Furthermore, its expression has also been reported in head and neck carcinoma (21), retinoblastoma (33), breast cancer $(34,35)$ and gastric cancer $(19)$. The activation of TRPM7 channels in human head and neck squamous carcinoma cell lines enhances proliferation (21), whereas TRPM7 knockdown by siRNA and the blockade of TRPM7 channels by $\mathrm{Gd}^{3+}$ or 2-APB, which exerts broad inhibitory effects on TRP superfamilies, including TRPM7, suppresses proliferation. The proliferation of human retinoblastoma cells is promoted by increasing spontaneous $\mathrm{Ca}^{2+}$ influx (33). Furthermore, the blockade of cation channel by $\mathrm{Gd}^{3+}, \mathrm{La}^{3+}$, LOE908, or 2-APB inhibits spontaneous $\mathrm{Ca}^{2+}$ influx and decreases the proliferation of retinoblastoma cells. TRPM7 channel-related proliferation is also associated with MCF-7 human breast cancer cells (35) and AGS human gastric adenocarcinoma cells (19). As previously demonstrated, the proliferation of both cells was prevented by TRPM7 protein knockout by siRNA transfection and by blocking TRPM7 channels with $\mathrm{La}^{3+}$ or 2-APB. Thus, TRPM7 channels may play an important role in valuable diagnostic and/ or prognostic markers, as well as targets for pharmaceutical intervention and more in depth investigations are required to elucidate the role TRPM7 channels in cancer (21).

In the present study, we found that quercetin inhibited TRPM7-like currents in AGS cells (Fig. 5B). To investigate the the effects of quercetin on TRPM7 channels, we overexpressed TRPM7 channels in HEK293 cells. It was found that quercetin inhibited the TRPM7 currents (Fig. 5C), and that its inhibitory effects were similar to those in the AGS cells. Therefore, we hypothesized that TRPM7 is involved in the apoptotic activity of quercetin in AGS cells.
TRPM7 has also been suggested to play a central role in: cellular $\mathrm{Mg}^{2+}$ homeostasis (36), central nervous system ischemic injury (37), skeletogenesis in zebrafish (38), defecation rhythm in Caenorhabditis elegans (39), cholinergic vesicle fusion with the plasma membrane (40), phosphoinositide3-kinase signaling in lymphocytes (41), and in osteoblast proliferation (42).

Apoptotic pathways are induced by a variety of signals, and a certain mechanism consistently implicated in apoptosis is the activation of a series of cytosolic proteases, that is, the caspases (43). Caspases are synthesized as inactive pro-enzymes that are processed in cells undergoing apoptosis by self-proteolysis and/or cleavage by another protein. Functionally, active caspases form a proteolytic cascade, which is capable of cleaving and activating specific substrates, including PARP (an enzyme involved in DNA repair and genomic maintenance). Cleavage events of this type may result in important alterations to normal homeostatic cellular processes (44). Furthermore, PARP has been shown to be a cellular target of caspase-3 and of other caspases. In our study, After $72 \mathrm{~h}$ of incubation with quercetin, PARP became proteolytically cleaved in AGS cells from its $116-\mathrm{kDa}$ intact form into $85-\mathrm{kDa}$ fragments (Fig. 2D), and caspase-3 activity increased accordingly (Fig. 2C).

In addition, we found that quercetin inhibited cell viability and that MAPK signaling pathways were involved in AGS cell apoptosis (Figs. 3 and 4). Furthermore, TRPM7 currents in AGS cells and in HEK293 cells which overexpress TRPM7 were inhibited by quercetin (Fig. 5B and C). Furthermore, in TRPM7-overexpressing HEK293 cells, quercetin induced cell death at a greater rate, suggesting that the upregulation of TRPM7 channels increases quercetin-induced cell death. These results suggest that quercetin plays an important pathophysiological role in AGS cells through MAPK signaling and TRPM7 channels. Accordingly, we suggest that quercetin be viewed as a potential drug for the pharmacological treatment of gastric cancer.

\section{Acknowledgements}

This study was supported by the Basic Science Research Program of the Korean National Research Foundation (NRF) funded by the Ministry of Education, Science and Technology (Grant no. 2010-0021347).

\section{References}

1. Ferlay J, Shin HR, Bray F, Forman D, Mathers C and Parkin DM: Estimates of worldwide burden of cancer in 2008: GLOBOCAN 2008. Int J Cancer 127: 2893-2917, 2010.

2. Bosman FT, Carneiro F, Hruban RH and Theise ND (eds): WHO Classification of Tumours of the Digestive System. Vol 3. 4th edition. IARC Press, Geneva, 2010.

3. Lowe SW and Lin AW: Apoptosis in cancer. Carcinogenesis. 21: 485-495, 2000.

4. Schmitt CA and Lowe SW: Apoptosis and therapy. J Pathol 187: 127-137, 1999.

5. Ishizawa K, Yoshizumi M, Kawai Y, Terao J, Kihira Y, Ikeda Y, Tomita S, Minakuchi K, Tsuchiya K and Tamaki T: Pharmacology in health food: metabolism of quercetin in vivo and its protective effect against arteriosclerosis. J Pharmacol Sci 115: 466-470, 2011.

6. Williams RJ, Spencer JPE and Rice-Evans C: Flavonoids: antioxidants or signaling molecules? Free Rad Biol Med 36: 838-849, 2004. 
7. Daskiewicz JB, Depeint F, Viornery L, Bayet C, ComteSarrazin G, Comte G, Gee JM, Johnson IT, Ndjoko K, Hostettmann K and Barron D: Effects of flavonoids on cell proliferation and caspase activation in a human colonic cell line HT29: an SAR study. J Med Chem 48: 2790-2804, 2005.

8. Surh YJ, Kundu JK, Na HK and Lee JS: Redox-sensitive transcription factors as prime targets for chemoprevention with anti-inflammatory and antioxidative phytochemicals. J Nutr 135 S2993-S3001, 2005

9. Kyle JA, Sharp L, Little J, Duthie GG and McNeill G: Dietary flavonoid intake and colorectal cancer: a case-control study. Br J Nutr 103: 429-436, 2010.

10. Stefani ED, Boffetta P, Deneo-Pellegrini H, Mendilaharsu M, Carzoglio JC, Ronco A and Olivera L: Dietary antioxidants and lung cancer risk: a case-control study in Uruguay. Nutr Cancer 34: 100-110, 1999.

11. van Erk MJ, Roepman P, van der Lende TR, Stierum RH, Aarts JM, van Bladeren PJ and van Ommen B: Integrated assessment by multiple gene expression analysis of quercetin bioactivity on anticancer-related mechanisms in colon cancer cells in vitro. Eur J Nutr 44: 143-156, 2005.

12. Dihal AA, de Boer VC, van der Woude H, Tilburgs C Bruijntjes JP, Alink GM, Rietjens IM, Woutersen RA and Stierum RH: Quercetin, but not its glycosidated conjugate rutin, inhibits azoxymethane-induced colorectal carcinogenesis in F344 rats. J Nutr 136: 2862-2867, 2006.

13. Duo J, Ying GG, Wang GW and Zhang L: Quercetin inhibits human breast cancer cell proliferation and induces apoptosis via Bcl-2 and Bax regulation. Mol Med Rep 5: 1453-1456, 2012.

14. Schönherr R: Clinical relevance of ion channels for diagnosis and therapy of cancer. J Membr Biol 205: 175-184, 2005.

15. Lehen'kyi V, Shapovalov G, Skryma R and Prevarskaya N: Ion channels and transporters in cancer. 5. Ion channels in control of cancer and cell apoptosis. Am J Physiol Cell Physiol 301: C1281-C1289, 2011

16. Wang BJ, Won SJ, Yu ZR and Su CL: Free radical scavenging and apoptotic effects of Cordyceps sinensis fractionated by supercritical carbon dioxide. Food Chem Toxicol 43: 543-552, 2005.

17. Hotz MA, Gong J, Traganos F and Darzynkiewicz Z: Flow cytometric detection of apoptosis: comparison of the assays of in situ DNA degradation and chromatin changes. Cytometry 15 237-244, 1994

18. Vermes I, Haanen C and Reutelingsperger C: Flow cytometry of apoptotic cell death. J Immunol Methods 243: 167-190, 2000.

19. Kim BJ, Park EJ, Lee JH, Jeon JH, Kim SJ and So I: Suppression of transient receptor potential melastatin 7 channel induces cell death in gastric cancer. Cancer Sci 99: 2502-2509, 2008.

20. Nadler MJ, Hermosura MC, Inabe K, Perraud AL, Zhu Q, Stokes AJ, Kurosaki T, Kinet JP, Penner R, Scharenberg AM and Fleig A: LTRPC7 is a Mg.ATP-regulated divalent cation channel required for cell viability. Nature 411: 590-595, 2001.

21. Jiang J, Li MH, Inoue K, Chu XP, Seeds J and Xiong ZG: Transient receptor potential melastatin 7-like current in human head and neck carcinoma cells: role in cell proliferation. Cancer Res 67: 10929-10938, 2007

22. Daker M, Ahmad M and Khoo AS: Quercetin-induced inhibition and synergistic activity with cisplatin - a chemotherapeutic strategy for nasopharyngeal carcinoma cells. Cancer Cell Int 12: 34, 2012.

23. Murakami A, Ashida $\mathrm{H}$ and Terao J: Multitargeted cancer prevention by quercetin. Cancer Lett 269: 315-325, 2008

24. Borska S, Chmielewska M, Wysocka T, Drag-Zalesinska M, Zabel $\mathrm{M}$ and Dziegiel P: In vitro effect of quercetin on human gastric carcinoma: targeting cancer cells death and MDR. Food Chem Toxicol 50: 3375-3383, 2012.

25. Wang P, Zhang K, Zhang Q, Mei J, Chen CJ, Feng ZZ and Yu DH: Effects of quercetin on the apoptosis of the human gastric carcinoma cells. Toxicol In Vitro 26: 221-228, 2012.
26. Wang K, Liu R, Li J, Mao J, Lei Y, Wu J, Zeng J, Zhang T, Wu H, Chen L, Huang $C$ and Wei Y: Quercetin induces protective autophagy in gastric cancer cells: involvement of Akt-mTORand hypoxia-induced factor $1 \alpha$-mediated signaling. Autophagy 7 : 966-978, 2011

27. Das S, Dey KK, Bharti R, MaitiChoudhury S, Maiti S and Mandal M: PKI 166 induced redox signalling and apoptosis through activation of p53, MAP kinase and caspase pathway in epidermoid carcinoma. J Exp Ther Oncol 10: 139-153, 2012.

28. Yuan L, Wang J, Xiao H, Wu W, Wang Y and Liu X: MAPK signaling pathways regulate mitochondrial-mediated apoptosis induced by isoorientin in human hepatoblastoma cancer cells. Food Chem Toxicol 53: 62-68, 2013.

29. Pearson G, Robinson F, Beers Gibson T, Xu BE, Karandikar M, Berman K and Cobb MH: Mitogen-activated protein (MAP) kinase pathways: regulation and physiological functions. Endocr Rev 22: 153-183, 2001.

30. Clapham DE: TRP channels as cellular sensors. Nature 426: 517-524, 2003

31. Pedersen SF, Owsianik G and Nilius B: TRP channels: an overview. Cell Calcium 38: 233-252, 2005.

32. Runnels LW, Yue L and Clapham DE: TRP-PLIK, a bifunctional protein with kinase and ion channel activities. Science 291: 1043-1047, 2001

33. Hanano T, Hara Y, Shi J, Morita H, Umebayashi C, Mori E, Sumimoto H, Ito Y, Mori Y, Inoue R: Involvement of TRPM7 in cell growth as a spontaneously activated $\mathrm{Ca}^{2+}$ entry pathway in human retinoblastoma cells. J Pharmacol Sci 95: 403-419, 2004

34. Dhennin-Duthille I, Gautier M, Faouzi M, Guilbert A, Brevet M, Vaudry D, Ahidouch A, Sevestre H and Ouadid-Ahidouch H: High expression of transient receptor potential channels in human breast cancer epithelial cells and tissues: correlation with pathological parameters. Cell Physiol Biochem 28: 813-822, 2011.

35. Guilbert A, Gautier M, Dhennin-Duthille I, Haren N, Sevestre H and Ouadid-Ahidouch $\mathrm{H}$ : Evidence that TRPM7 is required for breast cancer cell proliferation. Am J Physiol Cell Physiol 297: C493-C502, 2009.

36. Schmitz C, Perraud AL, Johnson CO, Inabe K, Smith MK, Penner R, Kurosaki T, Fleig A and Scharenberg AM: Regulation of vertebrate cellular $\mathrm{Mg}^{2+}$ homeostasis by TRPM7. Cell 114: 191-200, 2003.

37. Aarts M, Iihara K, Wei WL, Xiong ZG, Arundine M, Cerwinski W, MacDonald JF and Tymianski M: A key role for TRPM7 channels in anoxic neuronal death. Cell 115: 863-877, 2003.

38. Elizondo MR, Arduini BL, Paulsen J, MacDonald EL, Sabel JL, Henion PD, Cornell RA and Parichy DM: Defective skeletogenesis with kidney stone formation in dwarf zebrafish mutant for trpm7. Curr Biol 15: 667-671, 2005.

39. Vriens J, Owsianik G, Voets T, Droogmans G and Nilius B: Invertebrate TRP proteins as functional models for mammalian channels. Pflugers Arch 449: 213-226, 2004.

40. Brauchi S, Krapivinsky G, Krapivinsky L and Clapham DE: TRPM7 facilitates cholinergic vesicle fusion with the plasma membrane. Proc Natl Acad Sci USA 105: 8304-8308, 2008.

41. Sahni J and Scharenberg AM: TRPM7 ion channels are required for sustained phosphoinositide 3-kinase signaling in lymphocytes. Cell Metab 8: 84-93, 2008.

42. Abed E and Moreau R: Importance of melastatin-like transient receptor potential 7 and cations (magnesium, calcium) in human osteoblast-like cell proliferation. Cell Prolif 40: 849-865, 2007.

43. Patel T, Gores GJ and Kaufmann SH: The role of proteases during apoptosis. FASEB J 10: 587-597, 1996.

44. Lin C, Holland RE Jr, Donofrio JC, McCoy MH, Tudor LR and Chambers TM: Caspase activation in equine influenza virus induced apoptotic cell death. Vet Microbiol 84: 357-365, 2002. 